\title{
Implementing and Evaluating a Patient Safety Curriculum for Undergraduate Medical Students using Blackboard
}

\author{
Marwa A. El Naggar,
}

${ }^{1}$ Medical Education Unit, College of Medicine, Jouf University, KSA and ${ }^{2}$ Medical Education Department, Faculty of Medicine, Suez Canal University, Ismailia, Egypt

\begin{abstract}
Background: One of the important components of the medical school curricula is patient safety education. Aim: To introduce a WHO patient safety course in medical undergraduate curriculum College of Medicine Jouf University (COM JU) using blackboard, measuring students' attitudes and knowledge to patient safety course pre-post intervention. Methods: A quasi-experimental Pre-program/Post-program single group design was applied in this study. A comprehensive sample of $5^{\text {th }}$-year undergraduate medical students (COM JU) $(n=56)$ participated in the study. The first two levels of Kirkpatrick's evaluation of educational intervention were measured; the first level (learner satisfaction) measured using The Attitudes to Patient Safety Questionnaire (APSQ) and the second level (knowledge) where students completed locally designed multiple-choice items targeting patient safety basic information. To increase student's awareness of the course author conducted a World Health Organization (WHO) learning from errors workshop before the implementation of the course. The course was uploaded on the college's learning management system (Blackboard). Students' satisfaction with blackboard as a learning tool for patient safety course was measured. Results: We matched student pretest with posttest and used paired t-tests to identify mean differences. Response rate was $86.15 \%(n=56)$ of students. There was a statistically significant difference between genders regarding the importance of patient safety $(p$ $=0.004$ ). Results of (APSQ) showed that there was a minor improvement of attitude towards patient safety after the intervention. There was a statistically significant difference between students' knowledge test pre-post intervention (pre_42.86 \pm 12.17 -post_54.83 \pm 14.9 ) p 0.000. Seventythree percent $73 \%(n=41)$ of students agreed that Blackboard provided them with a positive learning experience. Conclusion: implementing a patient safety course into undergraduate medical education improved students' knowledge of patient safety, blackboard is an effective learning management system to teach a course online from a students' perspective.
\end{abstract}

Keywords: Attitudes to Patient Safety Questionnaire (APSQ), Patient safety, Medical curricula, Kirkpatrick, WHO workshop

\section{Introduction}

Patient safety education is an increasingly essential part of curricula for medical schools. Scientific advances in modern medicine dramatically enhance health outcomes, however, several research from various countries indicate that these benefits present major threats to patient safety ${ }^{(1)}$. Hospitalized patients are at risk of suffering an adverse event, and patients on medication have the risk of medication 
errors and side effects ${ }^{(2)}$. Although patient safety principles and concepts are required as a critical part of medical education and training, many medical educators are uncertain how best to integrate patient safety training into their programs and curricula(3). Many countries recognized the importance of educating health-care professionals on the principles and concepts of patient safety. The (WHO) was leading a global initiative to build on awareness, values and strategies for patient safety ${ }^{(4)}$. The College of Medicine, Jouf University COM$J U$ adopts an innovative problem-based learning curriculum, under faculty coaching members from diverse backgrounds in education and nationalities(5). COM-JU curriculum missed this subject it may be addressed in the hidden curriculum. Although Saudi-MED framework emphasize the important of patient safety in Saudi medical curriculums, within its Six competencies and 17 sub-competencies. The second theme is Patient care "The establishment and maintenance of essential clinical and interpersonal skills to demonstrate proficient assessment and delivery of patient-centered management"(6). COM-JU medical bachelor program's intended learning outcome number 7 (PLO7) stated "Place patients' needs and safety at the center of the care process". Medical education unit plan to introduce a patient safety course to reduce medical errors and to improve patient safety ${ }^{(7)}$. Little has been published evaluating medical student knowledge, and attitudinal changes following patient safety curriculum ${ }^{(8)}$. Agreement based recommendations accentuate the need for patient safety instruction of medical students, but thus data with respect to instructional techniques and educational plans has been restricted to experiences at single institutions. Majority of clerkship directors agree that there should be an explicit curriculum on patient safety instruction during medical school, most schools do not have such a curriculum ${ }^{(9)}$. The cornerstones of WHO curriculum include "the concepts of patient safety", What is human factors and Why is it important to patient safety? Understanding systems and the impact of complexity on patient care, Being an effective team player, Understanding and learning from errors, and Managing clinical risk, Introduction to quality improvement methods, Engaging with patients and careers, introduction to cluster topics putting knowledge into practice, minimizing infection through improved infection control, Patient safety and invasive procedures, improving medication errors (4), root cause analysis (RCA), evidence-based medicine, and communication"(7). COM-JU Medical students should finish many formal planned courses with specific credit hours, to be graduated, no slots in $5^{\text {th }}$ year timetables were available to incorporate a patient safety course, author decided to implement the course using blackboard after formal teaching hours, every students and faculty has his/her username and password to access blackboard. The aim of this study was introducing a patient safety course in medical undergraduate education at Jouf University using (LMS) blackboard learn, measure students attitude and knowledge with The Attitudes to Patient Safety Questionnaire (APSQ) and MCQs, finally measure students' satisfaction with using blackboard as the main instructional method to teach patient safety course.

\section{Subjects and Methods}

\section{Participants}

Comprehensive sample of $5^{\text {th }}$ year male and female undergraduate medical students (COM JU) ( $n=65), 56$ (86.15\%) of students participated. The optimal time to introduce patient safety is before the future physicians are exposed to the current "name, blame, and shame" of providers 
for adverse events ${ }^{(10)}$. This study was conducted in the problem-based curriculum of COM-JU, in the academic years 2019-2020.

\section{Research design}

A quasi-experimental Pre -program/postprogram single group designs was applied in this study. The study passed through two stages: "stage one" introduction of the course by WHO learning from errors workshop, "stage two" implementation and evaluation of the course. Workshop lasted for five hours in two sessions with one hour break, This workshop examined how multiple vulnerabilities could lead to error within the hospital system ${ }^{(1)}$, by the end students should understand why errors occur, what actions can be taken to improve patient safety, describe the importance of patient safety in hospitals and identify local policies and procedures to improve $i t^{(1)}$. At first facilitator disseminate the online link to (APSQ) and 60 items MCQs test to all the participants. First session facilitator outlined the goals and timetable of the workshop. The participant gave their name, position, and expectations of learning, then all watched 20-minute DVD drama depicting vincristine error, facilitator reviewed root cause analysis principles and answered questions, then explained fishbone technique, group technique applied to DVD drama. Each group got input on their main results, the Plenary discussion started. During second session students watched DVD error analysis based on five key factors, plenary discussion and brainstorming session on how errors can be avoided, roundtable where each participant said what they learned and what they would improve in their practice, and finally completed assessment forms $^{(1)}$. Modification of WHO patient safety course to be more suitable to be learnt through online learning platform. Most of worldwide colleges participated in evaluation of the WHO Multi-Professional
Patient Safety Curriculum Guide reported that the Guide could be adapted easily when needed ${ }^{(11)}$. One credit hour course was taught by flipped classroom using blackboard. course designed to be students centered. Students read online material which provides them with the required knowledge, followed by activities in the form of a discussion board, assignments which carried out to put the learned knowledge into action on the basis of new and evolving scientific information on the subject. Those skills possibly required a problem-based, immersive, "“experiential learning" environment, as postulated in adult learning theory ${ }^{(12)}$. Discussion board were addressing 'general perception of errors', 'error improvement strategies' " managing clinical risk:" infection control measures"(11,12). Assignments requested students to write how to report errors, cases scenarios and students requested to draw a fishbone to the suggested cause of errors, discussed the important role for patient involvement, differentiated the causes of error between individual and 'systems,' assessed the significance of reporting errors for organizational learning, and the probability of errors.

Methods of data collection and instruments. WHO patient safety workshop toolkit, videos, root cause analysis, workshop evaluation form were used. Statistical differences between male and female students' satisfaction with workshop were measured. The first two levels of Kirkpatrick's evaluation of educational intervention were measured(13), First level: The Attitudes to Patient Safety Questionnaire (APSQ) which contains 26 -items was used to measure the attitudes towards patient safety themes, its revealed nine interpretable factors, with good face validity, internal reliability ranging from 0.64 to 0.82 for the nine factors, and can differentiate answers from different groups. Nine factors are 
Patient safety training Received, Error reporting confidence, Working hours as error Cause, Error inevitability, Professional incompetence as error cause, Disclosure responsibility, Team functioning, Patient involvement in reducing error, Importance of patient safety in the curriculum, Items were measured on a Likert-type scale from 1 (strongly disagree) to 7 (strongly agree). APSQ developers declared that it could be used as a before and after measure to assess the success of changes in the undergraduate curriculum to incorporate patient safety training, The tool could also be used to measure attitudes or as an outcome measure in patient safety intervention studies $^{(14)}$. (APSQ) was completed anonymously on-line by google forms and disseminated in electronically via batch email, WhatsApp groups, blackboard with an online link, as it is the quickest and most cost-effective strategy. Kirkpatrick's level two students' knowledge was measured; a 60 items MCQs test was distributed to all the participants pre-post intervention in one-hour test. Researcher developed an online survey to test students' perception of blackboard as an effective learning tool for a patient safety course, it was created using Likert scale, from 1-disagree, 2-neutral to 3-agree.

\section{Ethical consideration}

Ethical approval was obtained from Jouf University ethics committee under the number of (16-02/41).

\section{Statistical Analysis}

Data was coded entered and processed using SPSS version 21.0 (IBM Corp. IBM SPSS Statistics for Windows). Continuous variables were expressed as mean \pm standard deviation (SD). Normal distribution of variables was checked by Shapirowilk (W) test. Scores across different domains before and after intervention were compared using paired $t$ test if the data followed normal distribution. Levene $s$ test of homogeneity was used to determine equal variance in pre \& post intervention groups. $p$ value < 0.05 was considered significant ${ }^{(15)}$. Descriptive statistics were performed and counted by number and percentage.

\begin{tabular}{|c|c|c|c|}
\hline \multicolumn{4}{|c|}{$\begin{array}{l}\text { Table 1: Fifth year students' evaluation of WHO patient safety } \\
\text { "learning from error" workshop }(n=56) \text {. }\end{array}$} \\
\hline Workshop Evaluation & $\begin{array}{l}\text { Male } \\
\mathrm{N}=33\end{array}$ & $\begin{array}{c}\begin{array}{c}\text { Female } \\
\mathrm{N}=23\end{array} \\
\end{array}$ & $\mathrm{p}$ value \\
\hline "The importance of patient safety in your clinical practice" & $4.83 \pm 0.51$ & $5.00 \pm 00$ & 0.172 \\
\hline "The importance of patient safety to your team." & $4.22 \pm 0.81$ & $5.00 \pm 00$ & $0.042 *$ \\
\hline $\begin{array}{l}\text { "The ability to identify factors in your workplace that are } \\
\text { likely to play a role in patient safety" }\end{array}$ & $3.94 \pm 1.06$ & $3.44 \pm 0.73$ & 0.107 \\
\hline "The easiest to suggest changes in your workplace" & $2.72 \pm 0.75$ & $3.22 \pm 0.44$ & $0.394^{*}$ \\
\hline $\begin{array}{l}\text { "The likeliness to suggest changes in your workplace in the } \\
\text { first three months of your internship" }\end{array}$ & $3.00 \pm 1.14$ & $3.00 \pm 1.12$ & $0.394^{*}$ \\
\hline $\begin{array}{l}\text { "The importance do you think of each of these factors in pa- } \\
\text { tient safety in your clinical area" }\end{array}$ & & & \\
\hline • "Standard operating procedures/guidelines" & $4.59 \pm 0.80$ & $5.00 \pm 00.0$ & 0.271 \\
\hline • "Communication" & $4.53 \pm 0.80$ & $4.33 \pm 0.71$ & 0.068 \\
\hline • "Training" & $4.59 \pm 0.71$ & $4.78 \pm 0.67$ & 0.257 \\
\hline • "Medication safety" & $4.38 \pm 0.89$ & $5.00 \pm 00.0$ & $0.304^{*}$ \\
\hline • "Patient engagement" & $4.38 \pm 0.72$ & $4.00 \pm 1.07$ & 0.158 \\
\hline "Overall evaluation of the workshop" & $4.06 \pm 0.66$ & $4.88 \pm 0.35$ & $0.001^{*}$ \\
\hline "The quality of the material provided" & $3.76 \pm 1.15$ & $5.00 \pm 00$ & $0.147^{*}$ \\
\hline "The relevance of the workshop to your clinical work" & $4.00 \pm 0.79$ & $5.00 \pm 00$ & $0.000 *$ \\
\hline
\end{tabular}




\section{Results}

Response rate was $86.15 \%$ (56/65), $92 \%$ (23/25) of female students and $82.5 \%$ (33/40) male students. Demographic data of students showed ages ranging from 23 to 26 (mean 24.36 years). All students are Saudi. The results were divided in three sections, data were collected from workshop evaluation form, APSQ, MCQs, blackboard evaluation form: respectively. Table 1 demonstrated the results obtained by comparing the mean of males' responses to those of their counterpart on workshop evaluation form items. There were statistically significant differences between males and females' responses in six of evaluation items. To reduce the tendency for response bias as for some items (those indicated by (R) in Table 2) a high score indicated mor negative beliefs about patient safety. In Table 2 a high score the items and variables in all analyzes suggests a more optimistic attitude towards patient health.

\begin{tabular}{|c|c|c|c|c|c|}
\hline \multicolumn{6}{|c|}{$\begin{array}{l}\text { Table 2: Pre-post intervention results of the Attitudes to } \\
\text { Patient Safety Questionnaire patient safety }(n=56)\end{array}$} \\
\hline Factors & Item & $\begin{array}{l}\text { scores pre } \\
\text { intervention } \\
(\mathrm{n}=56)\end{array}$ & $\begin{array}{l}\text { scores post } \\
\text { intervention } \\
\quad(n=56)\end{array}$ & $\begin{array}{c}\mathrm{t} \\
\text { value }\end{array}$ & $\begin{array}{c}P \\
\text { value }\end{array}$ \\
\hline \multirow{3}{*}{$\begin{array}{l}\text { 1. Patient } \\
\text { safety train- } \\
\text { ing received }\end{array}$} & $\begin{array}{l}\text { 1. My training prepares me to under- } \\
\text { stand the reasons behind medical } \\
\text { errors }\end{array}$ & $5.89 \pm 1.37$ & $6.06 \pm 0.93$ & -0.622 & .268 \\
\hline & $\begin{array}{l}\text { 2. As a result of my undergraduate } \\
\text { medical studies, I get a good under- } \\
\text { standing of patient safety concerns. }\end{array}$ & $3.54 \pm 2.11$ & $4.56 \pm 1.59$ & -1.669 & .051 \\
\hline & $\begin{array}{l}\text { 3. My training is preparing me to pre- } \\
\text { vent medical errors. }\end{array}$ & $5 \cdot 50 \pm 1.82$ & $5.75 \pm 1.65$ & 0.485 & .314 \\
\hline \multirow{3}{*}{$\begin{array}{l}\text { 2. Error re- } \\
\text { porting confi- } \\
\text { dence }\end{array}$} & $\begin{array}{l}\text { 4. I'd feel confident disclosing any mis- } \\
\text { takes I made, no matter how bad } \\
\text { the outcome was for the patient }\end{array}$ & $5.14 \pm 1.92$ & $5.00 \pm 1.26$ & 0.315 & .376 \\
\hline & $\begin{array}{l}\text { 5. I should feel confident disclosing } \\
\text { any mistakes that other patients } \\
\text { have made, no matter how bad the } \\
\text { patient's result was. }\end{array}$ & $5.07 \pm 1.73$ & $4.88 \pm 1.15$ & -0.403 & .344 \\
\hline & $\begin{array}{l}\text { 6. I am sure that I could talk freely with } \\
\text { my boss about a mistake that I had } \\
\text { made if it resulted in any possible or } \\
\text { real damage to my patient. }\end{array}$ & $5.82 \pm 1.54$ & $5.56 \pm 1.21$ & 0.618 & .269 \\
\hline \multirow{3}{*}{$\begin{array}{l}\text { 3. Working } \\
\text { hours as er- } \\
\text { ror cause }\end{array}$} & $\begin{array}{l}\text { 7. Shorter shifts would reduce medical } \\
\text { mistakes for physicians. }\end{array}$ & $5.79 \pm 1.54$ & $6.06 \pm 1.18$ & 0.520 & .302 \\
\hline & $\begin{array}{l}\text { 8. Doctors are at an elevated risk of } \\
\text { making errors by not taking daily } \\
\text { breaks during shifts. }\end{array}$ & $6.00 \pm 1.28$ & $5.94 \pm 1.84$ & 0.208 & .417 \\
\hline & $\begin{array}{l}\text { 9. The number of hours worked by doc- } \\
\text { tors increases the probability of mak- } \\
\text { ing medical mistakes. }\end{array}$ & $5.86 \pm 1.36$ & $5.94 \pm 1.29$ & 0.091 & .463 \\
\hline \multirow{2}{*}{$\begin{array}{l}\text { 4. Error inevi- } \\
\text { tability }\end{array}$} & $\begin{array}{l}\text { 10. Sometimes the doctors with the } \\
\text { most expertise and knowledge make } \\
\text { mistakes. }\end{array}$ & $5.36 \pm 1.54$ & $5.50 \pm 1.41$ & -0.290 & .386 \\
\hline & $\begin{array}{l}\text { 11. A real professional makes no errors } \\
\text { or mistakes }(R)\end{array}$ & $4.96 \pm 1.78$ & $5.25 \pm 1.88$ & -0.495 & .311 \\
\hline
\end{tabular}




\begin{tabular}{|c|c|c|c|c|c|}
\hline & \multicolumn{5}{|l|}{ Table 2 (Cont.) } \\
\hline & 12. Human errors are unavoidable. & $5.11 \pm 1.91$ & $4.88 \pm 1.96$ & 0.264 & .396 \\
\hline \multirow{4}{*}{$\begin{array}{l}\text { 5. Profes- } \\
\text { sional incom- } \\
\text { petence as } \\
\text { error cause }\end{array}$} & $\begin{array}{l}\text { 13. The bulk of medical mistakes stem } \\
\text { from negligent nurses }\end{array}$ & $4.13 \pm 1.80$ & $3.38 \pm 1.15$ & -0.936 & .177 \\
\hline & $\begin{array}{l}\text { 14. When people paid more attention at } \\
\text { work, averting medical errors }(R)\end{array}$ & $2.21 \pm 1.26$ & $2.06 \pm 1.12$ & -0.512 & .305 \\
\hline & $\begin{array}{l}\text { 15. The majority of medical errors stem } \\
\text { from incompetent doctors }(R)\end{array}$ & $3.48 \pm 1.93$ & $3.36 \pm 1.73$ & -1.228 & .113 \\
\hline & $\begin{array}{l}\text { 16. Medical errors are an indication of in- } \\
\text { competence }\end{array}$ & $4.14 \pm 1.79$ & $4.00 \pm 1.75$ & -0.476 & .318 \\
\hline \multirow{3}{*}{$\begin{array}{l}\text { 6. Disclosure } \\
\text { responsibility }\end{array}$} & $\begin{array}{l}\text { 17. It is not necessary to report errors } \\
\text { which do not result in adverse out- } \\
\text { comes for the patient (R) }\end{array}$ & $4.29 \pm 1.58$ & $4.50 \pm 1.16$ & -0.422 & .337 \\
\hline & $\begin{array}{l}\text { 18. Doctors are responsible for divulging } \\
\text { mistakes to patients only if they } \\
\text { cause patient damage }\end{array}$ & $4.57 \pm 1.45$ & $4.44 \pm 1.59$ & 0.421 & .337 \\
\hline & $\begin{array}{l}\text { 19. All medical errors should be re- } \\
\text { ported. }\end{array}$ & $3.46 \pm 1.18$ & $2.94 \pm 1.39$ & -1.370 & .088 \\
\hline \multirow{2}{*}{$\begin{array}{l}\text { 7. Team func- } \\
\text { tioning }\end{array}$} & $\begin{array}{l}\text { 20. Effective multidisciplinary coordina- } \\
\text { tion eliminates medical errors. }\end{array}$ & $6.03 \pm 1.31$ & $6.06 \pm 1.18$ & -0.074 & .470 \\
\hline & $\begin{array}{l}\text { 21. Teaching teamwork skills will elimi- } \\
\text { nate medical errors. }\end{array}$ & $5.78 \pm 1.20$ & $6.00 \pm 1.21$ & 0.090 & .464 \\
\hline \multirow{2}{*}{$\begin{array}{l}\text { 8. Patient in- } \\
\text { volvement in } \\
\text { reducing er- } \\
\text { ror }\end{array}$} & $\begin{array}{l}\text { 22. Patients play a vital role in avoiding } \\
\text { medical accidents. }\end{array}$ & $4.96 \pm 1.95$ & $4.94 \pm 1.34$ & 0.052 & .479 \\
\hline & $\begin{array}{l}\text { 23. Encouraging patients to engage } \\
\text { more in their treatment will help to } \\
\text { reduce the risk of medical errors. }\end{array}$ & $5.36 \pm 1.86$ & $5.27 \pm 3.72$ & 0.552 & .291 \\
\hline \multirow{3}{*}{$\begin{array}{l}\text { 9. Im- } \\
\text { portance of } \\
\text { patient } \\
\text { safety in the } \\
\text { curriculum }\end{array}$} & $\begin{array}{l}\text { 24. Teaching students about patient } \\
\text { safety should be a big focus in edu- } \\
\text { cating medical students. }\end{array}$ & $5.54 \pm 1.84$ & $5.94 \pm 1.48$ & -0.883 & .190 \\
\hline & $\begin{array}{l}\text { 25. Issues of patient safety cannot be } \\
\text { taught can only be learned by clinical } \\
\text { experience when qualified }(R)\end{array}$ & $3.89 \pm 2.14$ & $4.00 \pm 2.22$ & 0.049 & .480 \\
\hline & $\begin{array}{l}\text { 26. Learning about issues relating to pa- } \\
\text { tient safety before I qualify will allow } \\
\text { me to become a more effective doc- } \\
\text { tor. }\end{array}$ & $5.85 \pm 1.84$ & $6.19 \pm 1.38$ & -0.775 & .221 \\
\hline
\end{tabular}

Data are presented as Mean \pm SD

\section{Discussion}

Medical students need to understand and demonstrate the correct mindset, expertise, and skills to patient safety early and continuously ${ }^{(16)}$. The need to integrate patient safety into the undergraduate curriculum is a growing issue worldwide, several medical schools have recognized the need to educate the next generation of physicians in this modern patient safety para$\operatorname{digm}^{(17-19)}$. Female students showed more satisfaction with workshop than males, they found it relevance to their clinical work mean \pm SD $(5.00 \pm 00)$, in a study held Dumenco et $\mathrm{al}^{(20)}$ they assessed student satisfaction with the workshop; cross the 2 years, the mean overall rating was $75 \%$ (SD $=.89$ ) on the 5-point scale. Male students rated the quality of the workshop with a mean of (3.76 \pm 1.15$)$ in Dumenco et al study the overall quality of quality improvement/patient safety workshop mean was $(3.83 \pm 0.88)$. WHO patient safety course was implemented using blackboard that promotes pedagogical gain and constructivist perspectives ${ }^{(21)}$. In medical education, program reasoning, root cause analysis 
and application of the research and communication skills of the human factor were generally ignored, those skills are key to patient safety ${ }^{(10)}$. Modification of WHO patient safety curriculum to be more suitable to fully implemented by blackboard (3), flipping the classrooms, develop discussion board and interactive lectures, small group discussions and assignments. Author emphasis on active learning through practical exercises that complement the didactic material ${ }^{(10)}$. In a study held in COM JU by EI Naggar 2016, she identified learning styles preferences among students. Implementing many instructional methods that satisfied COMJU students' preferred learning styles that improve the learning, use, usability of information and the adaptability of students to problem-solving and reinforce deep learning circumstances ${ }^{(22)}$.

\begin{tabular}{|l|c|c|c|c|}
\hline \multicolumn{5}{|c|}{$\begin{array}{c}\text { Table 3: Pre-post intervention changes in the results of patient } \\
\text { safety knowledge test for medical students }(n=56)\end{array}$} \\
\hline Knowledge test & $\begin{array}{c}\text { Pre- intervention } \\
(n=56)\end{array}$ & $\begin{array}{c}\text { Post-intervention } \\
(n=56)\end{array}$ & T value & P value \\
\hline Male (40) & $42.59 \pm 13.97$ & $52.35 \pm 11.05$ & -5.586 & $0.000^{*}$ \\
\hline Female (25) & $43.13 \pm 10.42$ & $57.31 \pm 18.75$ & -3.781 & $0.000^{*}$ \\
\hline Total (65) & $42.86 \pm 12.17$ & $54.83 \pm 14.9$ & -6.477 & $0.000^{*}$ \\
\hline
\end{tabular}

Data are presented as Mean \pm SD

Results of the study shows minor increase in means of few items of in attitude scale (APSQ) post- intervention without statistically significance differences pre-post intervention, as change of students' attitude need more time. Change of students' attitude needs long time. Author recommend incorporate patient safety concept early in the curriculum in problem-based learning scenarios, team-based learning cases in seminars, and encourage clinicians to emphasize importance of patient safety in hospital training so by time students get the concept, change their attitude towards patient safety. Results showed that error reporting confidence factor post-intervention means were less than pre intervention mean, with respect to the item "all medical errors should be reported" (pre 3.46 \pm 1.18 _post 2.94 $\pm 1.39 \mathrm{P} .088673$ ) students were felling more confident to report errors before intervention, they may know the consequences of reporting errors on health care team, but they afraid of reprisal, this point needs more further investigations. This result matched with the results of APSQ developer Sam Carruthers et al 2009 they found that tutors showed less faith in reporting a mistake without fear of reprisal, a perception which may derive from personal experience of guilt ${ }^{(14)}$. Results found a significant pre-post increase in patients safety knowledge among medical students. The study results are encouraging, suggesting introducing WHO patient safety course in the official curriculum as a compulsory course for undergraduate students. Current study results are consistent with many studies that demonstrated increases in knowledge levels and self-efficacy after participating in short courses on patient safety $(7,12,23-26)$. During one month of patient safety course, students recognize the importance of considering patient safety while dealing with patients, and identify the causes of error, how to follow patient safety hospitals plan and the system and suggest improvement plan for it. Our study results are consistent with studies of Halbach et al 2005, Patey et al 2007 and Hall et al 2010; they found that a 4-5 h patient safety curriculum at New York Medical College, Aberdeen Royal and The University of Missouri-Columbia increased perceived skills for medical error disclosure and increased awareness of the incidence 
of medical errors $(24,27,28)$. Using blackboard to fully implement patient safety course in COM JU was the first experience of pure on line e-learning course, it occurred before the forced shift to e-learning due to COVID 19 pandemic, so the experience of uploading asynchronous lectures, synchronous virtual classrooms, discussion board and assignments, conducting online MCQs exams, students staff electronic communication, monitoring and academic advising using blackboard. We recommend using simulation-based learning in college that will help students to master skills in safe learning environment, prevent future harm to patients and enhance patients' safety ${ }^{(29)}$. Seventy five percent (42) of 5 th year students stated that they considered blackboard a real platform for interaction between the instructor and the students, $72 \%$ (40) were pleased with the general ease of its use. In a study held by Alokluk, $2018^{(20)}$, she claimed that blackboard offers a collaborative and user-friendly teachinglearning environment in terms of collaboration, assessment and across all information management systems. In a another study held by Uziak et al., 2018(30), they found that students were generally comfortable with Blackboard as a learning tool; they did not feel any stress related to using it (89\%), they were also pleased with the general ease of use of the platform. Further points for investigation is to implement patient safety course to inter professional group of health professions students, to bridge building and strengthening teamwork based on a shared safety culture, and to study the impact of implementing a patient safety course in students' performance in hospitals after graduation. Based on the results and with support from authorities, curriculum, and study plan committee incorporation a patient safety course one credit hour in the new study plan for fourth year students as it's the first year in the clinical phase. One of the challenges faced by the author that faculty members had little or no knowledge of patient safety and its importance. This will required conduct a faculty development training for the faculty. Limitation of the study that college has no certified trained staffs on patient safety, so workshop was presented and managed by the author, and most of the lectures, classes, discussion forum were given by the researcher with help of few faculty. lack of interest of busy clinician to participate in teaching the course, some topics need to be elaborated in workplace by trained clinicians. Some students lost their motivation to teach online, after official teaching hours, course that did count in their credit hours and GPA. Difficulty to empty timetable for one day to face to face "learning from errors" workshop. some internet connection problems face students. Students cheating on online exams. Author did not assess trainees' ability to apply key patient safety principles in real clinical scenario.

\section{Conclusion}

The study concludes that implementing a patient safety course into undergraduate medical education improved students' knowledge of patient safety, blackboard is an effective learning management system to teach course online from students' perspective.

\section{Acknowledgement}

The authors acknowledge medical education experts who revised the modified WHO patient's safety course, college's elearning coordinator, $5^{\text {th }}$ year students for their generous contributions in time, insight, and support to make this course successful.

Disclaimer: None.

Conflict of interests: None.

Source of Funding: None 


\section{References}

1. Nie, Y., Li, L., Duan, Y. et al. Patient safety education for undergraduate medical students: a systematic review. BMC Med Educ 11, 33 (2011).

2. World Health Organization. Patient safety workshop: learning from error. World Health Organization. 2010.

3. Goolsarran NE. Hamo C, Lane S, Frawley $S$ and Wei-Hsin Lu. Effectiveness of an interprofessional patient safety team-based learning simulation experience on healthcare professional Trainees, BMC Medical Education,2018, 18:192

4. World Health Organization, WHO Patient Safety Curriculum Guide for Medical Schools. ISBN 9789241598316 (NLM classification: WX 167), World Health Organization, 2009.

5. El Naggar MA, Needs Assessment for a Longitudinal Faculty Development Program at the College of Medicine, Aljouf University, Sakaka, Saudi Arabia, Aljouf University Medical Journal (AUMJ), 2016 March 1; 3(1).

6. Zaini RG, Bin Abdulrahman KA, Al-Khotani AA, Al-Hayani AM, Al-Alwan IA, and Jastaniah SD. Saudi Meds: A competence specification for Saudi medical graduates. Med Teach. 2011; 33:582-4.

7. Seiden SC, Galvan C, Lamm R. Role of medical students in preventing patient harm and enhancing patient safety. Qual Saf Health Care. 2006; 15:272-6.

8. Thompson DA, Cowan J, Holzmueller C, Albert $\mathrm{W} \mathrm{Wu}$, Bass $\mathrm{E}$, Pronovost $\mathrm{P}$. Planning and implementing a systemsbased patient safety curriculum in medical education. Am J Med Qual 2008; 23:271 e8.

9. Alper E, Eric; Rosenberg El, et al. Patient Safety Education at U.S. and Canadian Medical Schools: Results From the 2006 Clerkship Directors in Internal Medicine Survey, Academic Medicine: December 2009-84 (12), p 1672-1676.

10. Davis DA, Thomson MA, Oxman AD, Haynes RB. Changing physician performance. A systematic review of the effect of continuing medical education strategies. JAMA. 1995 Sep 6;274(9): 700-5.

11. Thompson DA, Cowan J, Holzmueller C, Wu AW, Bass E, Pronovost P. Planning and implementing a systemsbased patient safety curriculum in medical education. Am J Med Qual. 2008 Jul-Aug; 23 (4):271-8.

12. Farley $D$, Zheng $H$, Rousi E, Leotsakos A, Evaluation of the WHO Multi-Professional Patient Safety Curriculum Guide, 2013, Patient Safety Program, World Health Organization, Switzerland.

13. Kirkpatrick D.L. (1998) The Four Levels of Evaluation. In: Brown S.M., Seidner C.J. (eds) Evaluating Corporate Training: Models and Issues. Evaluation in Education and Human Services, vol 46. Springer, Dordrecht.

14. Carruthers S, Lawton R, Sandars J, Howe A, Perry M. Attitudes to patient safety amongst medical students and tutors: Developing a reliable and valid measure. Med Teach. 2009 Aug;31(8): e370-6.

15. Dupont WD. Statistical Modeling for Biomedical Researchers, 2nd Edition. Cambridge, U.K: Cambridge University Press. 2008.

16. Myung SJ, Shin JS, Kim JH, et al. The Patient Safety Curriculum for Undergraduate Medical Students as a First Step Toward Improving Patient Safety, J Surg Edu, 2012, 69;5:659- 4.

17. Dickey NW. Patient safety and medical education: a partnership for the future. Tex Med. 2002; 98:55-9.

18. Tsai TC, Bohnen JD, Hafiz S. Instruction in quality improvement and patient safety must be a priority in medical students' education. Acad Med. 2010; 85:743-4.

19. Varkey P, Karlapudi S, Rose S, Swensen S. A patient safety curriculum for graduate medical education: results from a needs assessment of educators and patient safety experts. Am J Med Qual. 2009; 24:214-1.

20. Dumenco L, Monteiro K, George P, McNicoll L, Warrier S, Dollase R. An interactive quality improvement and 
patient safety workshop for first-year medical students. MedEdPORTAL. 2018; 14:10734.

21. Alokluk JA. The Effectiveness of Blackboard System Uses and Limitations in Information Management. Intelligent Information Management, 2018, 10, 133-49.

22. El Naggar MA, Identifying and Comparing Learning Styles Preferences among Medical Undergraduates Students at College of Medicine Aljouf University. Intel Prop Rights. (2016), 1-6. S1: 011.

23. Aboumatar HJ, Thompson D, Wu A, et al. Development and evaluation of a 3day patient safety curriculum to advance knowledge, self-efficacy and system thinking among medical students. BMJ Qual Saf. 2012 May;21(5):416-22.

24. Halbach JL, Sullivan LL. Teaching medical students about medical errors and patient safety: evaluation of a required curriculum. Acad Med. 2005 Jun;80(6):600-6.

25. Madigosky WS, Headrick LA, Nelson K, Cox KR, Anderson T. Changing and sustaining medical students' knowledge, skills, and attitudes about patient safety and medical fallibility. Acad Med. 2006 Jan;81(1):94-101.

26. Moskowitz E, Veloski JJ, Fields SK, Nash DB. Development, and evaluation of a 1-day interclerkship program for medical students on medical errors and patient safety. Am J Med Qual. 2007 Jan-Feb; 22 (1): 13-7.

27. Patey R, Flin R, Cuthbertson BH, MacDonald L, Mearns K, Cleland J, Williams D. Patient safety: helping medical students understand error in healthcare. Qual Saf Health Care. 2007 Aug;16(4):256-9.

28. Hall LW, Scott SD, Cox KR, et al. Effectiveness of patient safety training in equipping medical students to recognise safety hazards and propose robust interventions. BMJ Quality \& Safety 2010;19:3-8.

29. El Naggar MA, Al Maeen AH, Students' perception towards medical-simulation training as a method for clinical teaching, J Pak Med Assoc, 2020, 70: 618-623.

30. Uziak, J, Oladiran M, Lorencowicz E, and Becker K, "Students' and Instructor's Perspective on the use of Blackboard Platform for Delivering an Engineering Course" Engineering Education Faculty Publications. (2018), 237. 